\title{
CORIORRETINOPATÍA GEOGRÁFICA PROGRESIVA ASOCIADA AL SÍNDROME DE ALAGILLE
}

\section{PROGRESSIVE GEOGRAPHIC CHORIORETINOPATHY ASSOCIATED WITH ALAGILLE SYNDROME}

\author{
BIDAGUREN A ${ }^{1}$, BLANCO A ${ }^{1}$, GIBELALDE A ${ }^{1}$, IRIGOYEN $\mathrm{C}^{1}$
}

\section{RESUMEN}

Caso clínico: Paciente diagnosticada genéticamente de Síndrome de Alagille, vista en el servicio de oftalmología desde 1992 por atrofia coriorretiniana progresiva que ha dado lugar a una pérdida severa de agudeza visual bilateral.

Discusión: Las manifestaciones oftalmológicas asociadas al síndrome de Alagille son variables, pudiendo afectarse la práctica totalidad de las estructuras oculares. A pesar de que hasta el momento no se han descrito alteraciones severas de la agudeza visual ni progresión de las lesiones oculares asociadas al síndrome de Alagille, nuestra paciente ha presentado una marcada disminución de su agudeza visual así como una clara progresión de las lesiones coriorretinianas.

Palabras clave: Síndrome de Alagille, gen Jagged 1 , coriorretinopatia, coroiditis serpiginosa, embriotoxon posterior.

\begin{abstract}
Case report: We report the case of a patient with the genetic diagnosis of Alagille Syndrome, who has attended our hospital since 1992, and has shown a progressive bilateral chorioretinopathy with severe deterioration in visual acuity.

Discussion: Ocular abnormalities associated with Alagille Syndrome are variable and can affect most ocular structures. Although severe visual threat or progressive ocular disease associated with Alagille syndrome have not yet been described, our patient has shown a marked decrease in visual acuity and a clear progression of the chorioretinal atrophy (Arch Soc Esp Oftalmol 2007; 82: 513-516).
\end{abstract}

Key words: Alagille Syndrome, Jagged 1 gene, chorioretinopathy, serpiginous choroiditis, posterior embriotoxon.

\section{INTRODUCCIÓN}

El Síndrome de Alagille (SA) es una enfermedad familiar de herencia Autosómica Dominante con penetrancia y expresividad variable, caracterizada clínicamente por presentar ictericia colestásica neonatal e hipoplasia de los conductos biliares intrahe- páticos (1). Se han detectado mutaciones en el gen Jagged 1 que codifica un ligando del receptor notch transmembrana (2).

Las manifestaciones oftalmológicas asociadas a este síndrome son variables, siendo el embriotoxon posterior, criterio mayor para el diagnóstico del síndrome, la más frecuente de todas ellas (3). La hipo-

\footnotetext{
Recibido: 21/7/06. Aceptado: 12/6/07.

Servicio de Oftalmología. Hospital Donostia. San Sebastián (Guipúzcoa). España.

1 Licenciado en Medicina.

Correspondencia:

Aritz Bidaguren Urbieta

Paseo Dr. Marañón, $14,3 .^{\circ} \mathrm{C}$

20009 San Sebastián (Guipúzcoa)

España

E-mail: aritzbidaguren@kaixo.com
} 
pigmentación difusa del epitelio pigmentario de la retina (EPR) es la alteración retiniana más constante en estos pacientes.

\section{CASO CLÍNICO}

Paciente mujer, vista por primera vez en el servicio de oftalmología de nuestro hospital en el año 1992 (a los 33 años) por disminución de la agudeza visual de su ojo derecho. La exploración oftalmológica inicial mostró una agudeza visual (AV) de 0,2 en ojo derecho (OD) y de 0,6 en ojo izquierdo (OI), con $-5,0$ y $-4,0$ dioptrías esféricas respectivamente. En el examen biomicroscópico de polo anterior se apreciaba un embriotoxon posterior marcado (fig. 1) y la presión intraocular era de $12 \mathrm{mmHg}$ en ambos ojos. El fondo de ojo de la paciente mostraba las siguientes características (fig. 2) OD: Atrofia geográfica circumpapilar del EPR y coroides con límites precisos que abarca todo el área macular y permite visualizar los vasos coroideos subyacentes. OI: Lesiones difusas de características similares a las del OD, con semiluna de atrofia que afecta parcialmente el área macular. Ante esta situación se realizó una angiografía fluoresceínica (AFG) que mostraba la atrofia del EPR y coriocapilar ya descrita, sin claros signos de actividad. Ante la posibilidad de que se tratara de una coroiditis serpiginosa, se inició tratamiento inmunosupresor con Corticoides y Ciclosporina, además de suplementos vitamínicos por un posible déficit nutricional, sin que se objetivara respuesta favorable. Con posterioridad, y

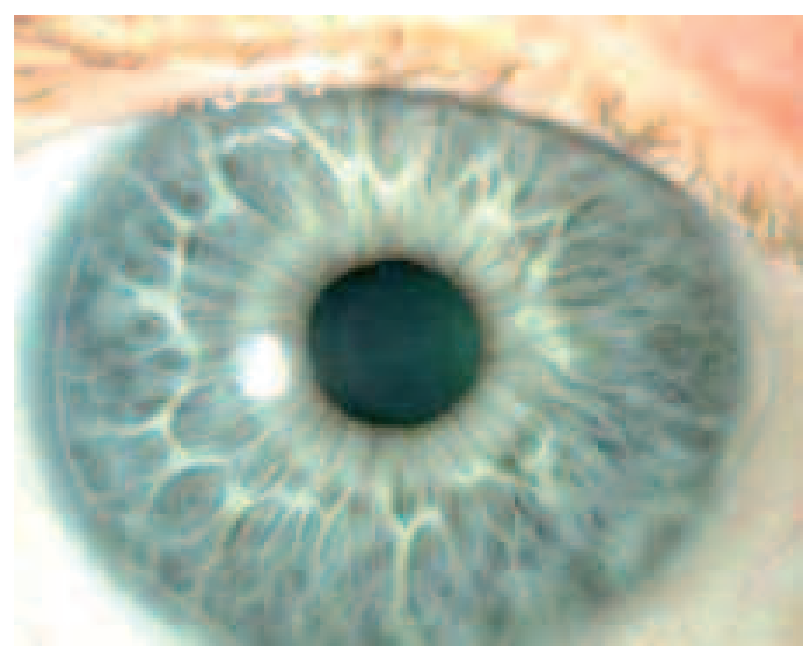

Fig. 1: Embriotoxon posterior.

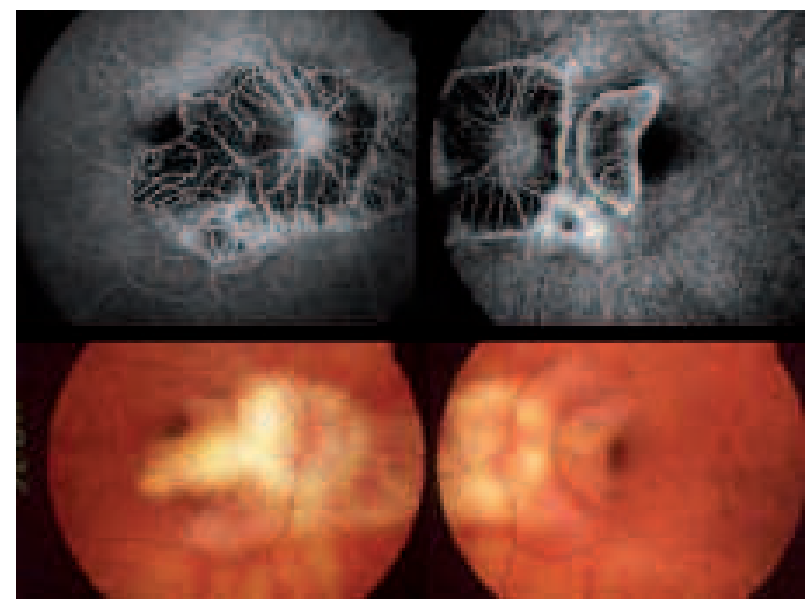

Fig. 2: Año 1992. Retinografías y angiografías iniciales que muestran una atrofia geográfica circumpapilar bilateral con respeto parcial del área macular del ojo izquierdo.

debido a la evolución desfavorable, se reinstauró tratamiento inmunosupresor con Azatioprina y Metotrexate sin presentar, en ningún momento, signo alguno de mejoría.

En el año 2003, y debido a sus antecedentes familiares (2 sobrinos diagnosticados genéticamente de Síndrome de Alagille sin manifestaciones oftalmológicas asociadas), se realiza estudio genético a la paciente, descubriendo la mutación $2785+3$ del AAGT en el intrón 19 del gen Jagged 1 y confirmando así la sospecha de Síndrome de Alagille.

En la actualidad, y tras 14 años de seguimiento, la paciente presenta una agudeza visual de percepción de luz en OD y 0,1 con fijación excéntrica en OI. En el fondo de ojo se objetiva el crecimiento de las lesiones atróficas coriorretinianas que abarcan completamente el área macular sin haber mostrado evidencia alguna de signos angiográficos de actividad en los controles periódicos realizados a lo largo del seguimiento en nuestro servicio (fig. 3).

\section{DISCUSIÓN}

Existen en la literatura 11 series con al menos 57 pacientes en los que se han estudiado las manifestaciones oftalmológicas asociadas al Síndrome de Alagille (3-5). Además de la presencia casi universal del embriotoxon posterior, criterio diagnóstico mayor del síndrome, las manifestaciones oftalmológicas abarcan la práctica totalidad de las estructuras 


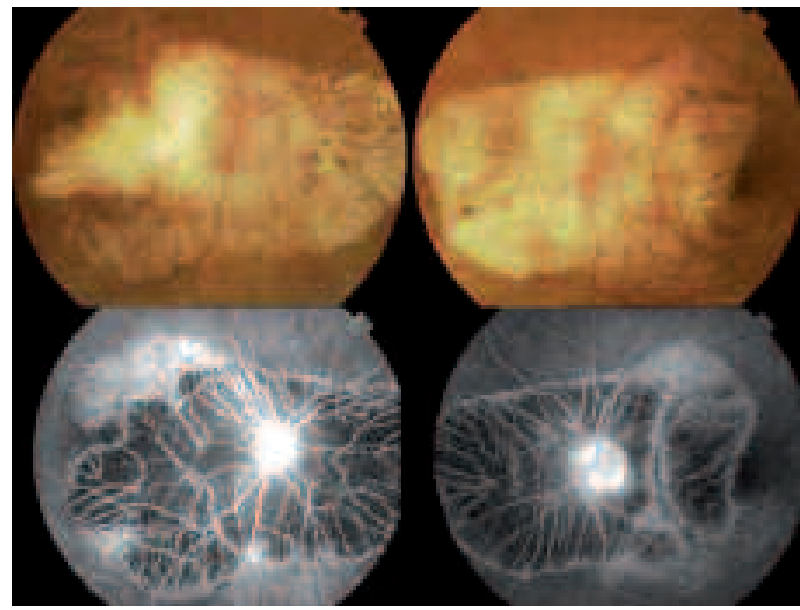

Fig. 3: Año 2006. Retinografías y angiografias que muestran la progresión de las lesiones previas que en la actualidad abarcan todo el área macular.

oculares y varían considerablemente de unas series a otras. Hingorani et al (3) en la mayor de las series de pacientes con manifestaciones oftalmológicas asociadas al síndrome de Alagille, detectan anomalías funduscópicas en el $90 \%$ de los pacientes afectos, de los cuales el 57\% muestra una hipopigmentación difusa del EPR, siendo esta la manifestación más constante de todas las encontradas. Sin embargo, y a pesar del alto número y variabilidad de manifestaciones oftalmológicas, los diferentes autores destacan la ausencia de disminución significativa de la agudeza visual y de progresión de estas lesiones (3).

Inicialmente, nuestra paciente presentaba lesiones atróficas coriorretinianas bilaterales que nos hicieron pensar en una coroiditis serpiginosa como primera opción diagnóstica. Pese al tratamiento inmunosupresor, las lesiones progresaron sin que se objetivaran signos de actividad angiográfica en ningún momento, dando lugar a un progresivo deterioro estructural y funcional, con marcada disminu- ción de la agudeza visual. Esta falta de respuesta al tratamiento, así como la ausencia de actividad inflamatoria en los sucesivos controles angiográficos realizados en los episodios de agravamiento de los síntomas nos hizo replantearnos el diagnóstico. En la actualidad, nuestra primera opción diagnóstica es la de una distrofia coriorretiniana peripapilar asociada de forma casual al síndrome de Alagille aunque pudiera también tratarse de una coroiditis serpiginosa de curso más indolente. La distrofia coriorretiniana peripapilar se caracteriza por la presencia de cambios circunscritos a la coriocapilar, a diferencia de los pacientes afectos de síndrome de Alagille en los que la coroides está intacta (5). En su evolución, estos pacientes desarrollan cicatrices pigmentadas con atrofia del EPR y la coriocapilar, pudiendo, como en nuestra paciente, asociar focos secundarios adyacentes en polo posterior.

Señalar como conclusión, la existencia de esta asociación no descrita hasta la fecha así como la concurrencia de una patología con severo deterioro visual en una paciente afecta de síndrome de Alagille.

\section{BIBLIOGRAFÍA}

1. Alagille D, Odievre M, Gautier M, Dommergues JP. Hepatic ductular hypoplasia associated with characteristic facies, vertebral malformations, retarded physical, mental, and sexual development, and cardiac murmur. $J$ Pediatr 1975; 86: 63-71.

2. Oda T, Elkahloun AG, Pike BL, Okajima K, Krantz ID, Genin A, et al. Mutations in the human Jagged 1 gene are responsible for Alagille syndrome. Nat Genet 1997; 16: 235-242.

3. Hingorani $M$, Nischal KK, Davies A, Bentley C, Vivian A, Baker AJ, et al. Ocular abnormalities in Alagille Syndrome. Ophthalmology 1999; 106: 330-337.

4. Ricci B, Lepore D, Iossa M, Santo A, Chiaretti A. Ocular anomalies in Alagille's syndrome. J Fr Ophtalmol 1991; 14: 481-485.

5. Johnson BL. Ocular pathologic features of arteriohepatic dysplasia (Alagille's syndrome). Am J Ophthalmol 1990; 110: 504-512. 